\title{
Luminance thresholds for the Bezold-Brücke hue shift'
}

\author{
V. C. SMITH, ${ }^{2}$ J. POKORNY, ${ }^{2}$ J. COHEN, ${ }^{3}$ AND T. PERERA \\ COLUMBIA UNIVERSITY
}

This study presents data on the luminance difference at which a hue difference is first perceived between two identical spectral lights. Thresholds were obtained for both luminance increments and decrements from a $2.00 \mathrm{log}$ troland standard for wavelengths between $470 \mathrm{~nm}$ and $690 \mathrm{~nm}$. A predicted luminance threshold for each wavelength was calculated based on wavelength discrimination data and the Purdy constant hue contours; i.e. that luminance at which the constant hue contour intersects the wavelength discrimination bound for a given wavelength. A generally good agreement was obtained between observed and predicted values.

The Bezold-Brücke phenomenon refers to the apparent change in color as a stimulus changes in luminance. Purdy (1931) performed the first major parametric study of the phenomenon, using a range of illumination of 1.0 to $3.3 \mathrm{log}$ trolands and a monocular view of a circular $3^{\circ}$ bipartite field. The luminance of one half of the field was about one $\log$ unit higher than the other half of the field. The subject (Purdy, himself) adjusted the wavelength of the dimmer field until the two halves were "matched in hue." purdy remarks:

The hue matches which one thus obtains are never perfect. For example, a yellow at low intensity has a brownish tinge which is not found in a brighter yellow. Also, the difference in brilliance and saturation between the two sides of the field makes the comparison exceedingly difficult, and much practice is required in order to make the judgments.
As Boynton and Gordon (1965) have pointed out, there are two possible artifacts in Purdy's method. First, hue varies as a function of stimulus duration, and Purdy allowed viewing of the field for an indefinite period. Second, Purdy presented his stimulus fields side by side and so allowed for strong induction effects. In spite of these criticisms, more recent investigations of the Bezold-Brücke phenomenon (Akita \& Graham, 1966; Boynton \& Gordon, 1965; Dagher, Cruz, \& Plaza, 1958; and Luria, 1967) show approximate replication of the Purdy functions.

Akita and Graham (1966), Boynton and Gordon (1965) and Luria (1967) followed Purdy in using a constant difference (usually one log unit) in the luminances of the high and low luminance test patches. Dagher, Cruz, and Plaza (1958) varied the radiant energy of the stimulus to obtain first an absolute threshold, a threshold at which color is first reported, and a radiance at which the $S$ reports "maximal saturation." The change in radiant energy between the first report of color and the report of maximal saturation ranged from 0.5 to $2.0 \mathrm{log}$ units. For various color names, including "green," "yellow," "orange," and "red," they demonstrate a shift in wavelength between the energy at which this color name first appeared, and the energy at which it appeared with full saturation. This energy difference, of course, varies for different color names. The direction of shift, with the exception of the "red" hues for one $O$, is consonant with Purdy's data.

The purpose of the research reported here was

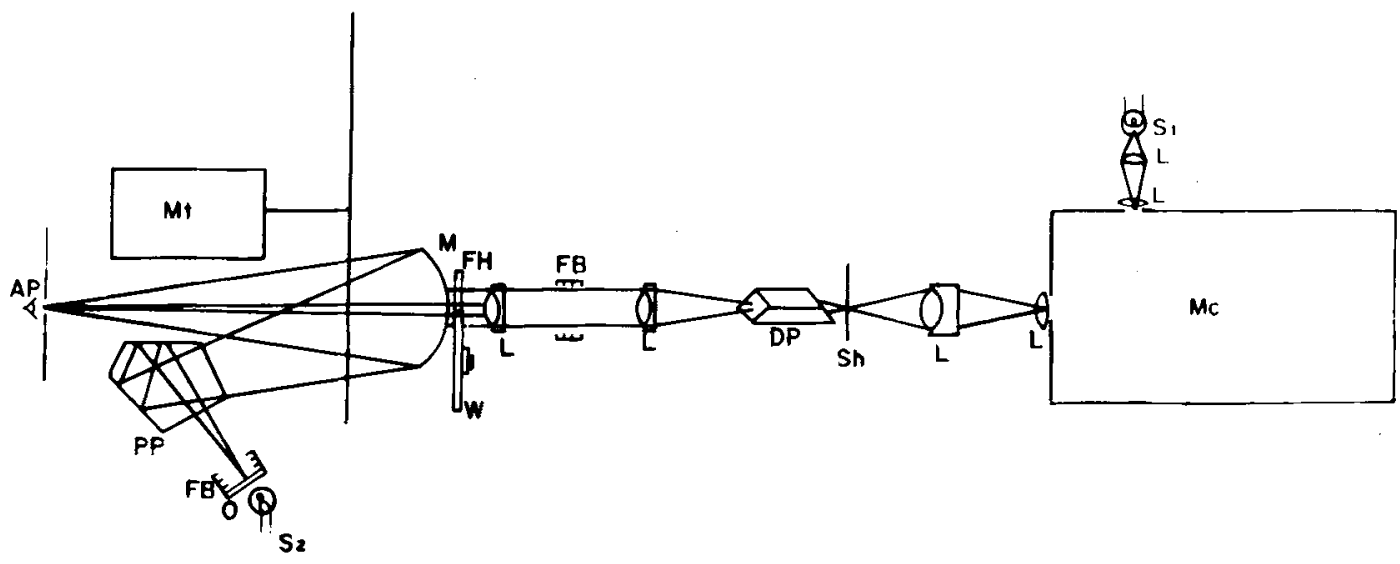

Fig. 1. Diagram of optical system. See text for further description. 
(a) to find the threshold change in luminance necessary to observe a hue shift at a fixed luminance level for a range of wavelengths in the visible spectrum, and (b) to relate such findings to the results obtained when the Bezold-Brücke phenomenon is measured with a fixed luminance difference between two fields. Thresholds were obtained for both an increase and a decrease in luminance from a fixed comparison luminance level.

\section{Apparatus}

\section{METHOD}

A schematic of the apparatus is shown in Fig. 1. Light from the vertical exit slit of a Bausch and Lomb grating monochromator (Mc), band pass $15 \mathrm{~nm}$, is focused on the vane of a disc shutter (Sh), and then passes through a Dove prism (DP) oriented at a $45^{\circ}$ angle, exiting as a horizontal slit of light. The horizontal slit of light is then focused by a pair of lenses on the $1.5 \mathrm{~mm}$ artificial pupil (AP). A front surface spherical mirror (M), with two circular holes ground in a horizontal plane, interrupts the beam as it converges on the pupil. The two circles form the test patches, each subtending a visual angle of approximately $1^{\circ}$, their centers being separated by $2^{\circ}$ of visual angle. The spherical mirror serves as the surround. A second light source $\left(\mathrm{S}_{2}\right)$ is re- flected off the mirror and brought to a focus at the artificial pupil.

The shutter consisted of a $6 \mathrm{rpm}$ synchronous motor driving a disc from which a sector of $36^{\circ}$ had been removed, giving an exposure time of 1 sec every $10 \mathrm{sec}$.

A filter box (FB) was placed in the common path for use of both Corning glass and neutral filters. Corning glass blocking filters were used below $500 \mathrm{~nm}$ and above $590 \mathrm{~nm}$ to minimize scatter and to eliminate the second order spectrum. A filter holder ( $\mathrm{FH}$ ) allowing the insertion of fixed neutral filters was placed before the test patch on the S's left. A Wratten Neutral Density wedge (W) was placed before the other test patch allowing continuous adjustment of the luminance of that patch over a 2 log unit range. The neutral density filters were calibrated for relative spectral transmittance on a Beckman Model DU spectrophotometer and found to have essentially uniform transmittance from 450 to $700 \mathrm{~nm}$. Their nominal density values were checked on the Martens photometer. The neutral density wedge was calibrated at the artificial pupil at $50 \mathrm{~nm}$ steps throughout the spectrum with a Welch electronic photometer which had previously been calibrated against the neutral density filters.

The output of the monochromators was calibrated

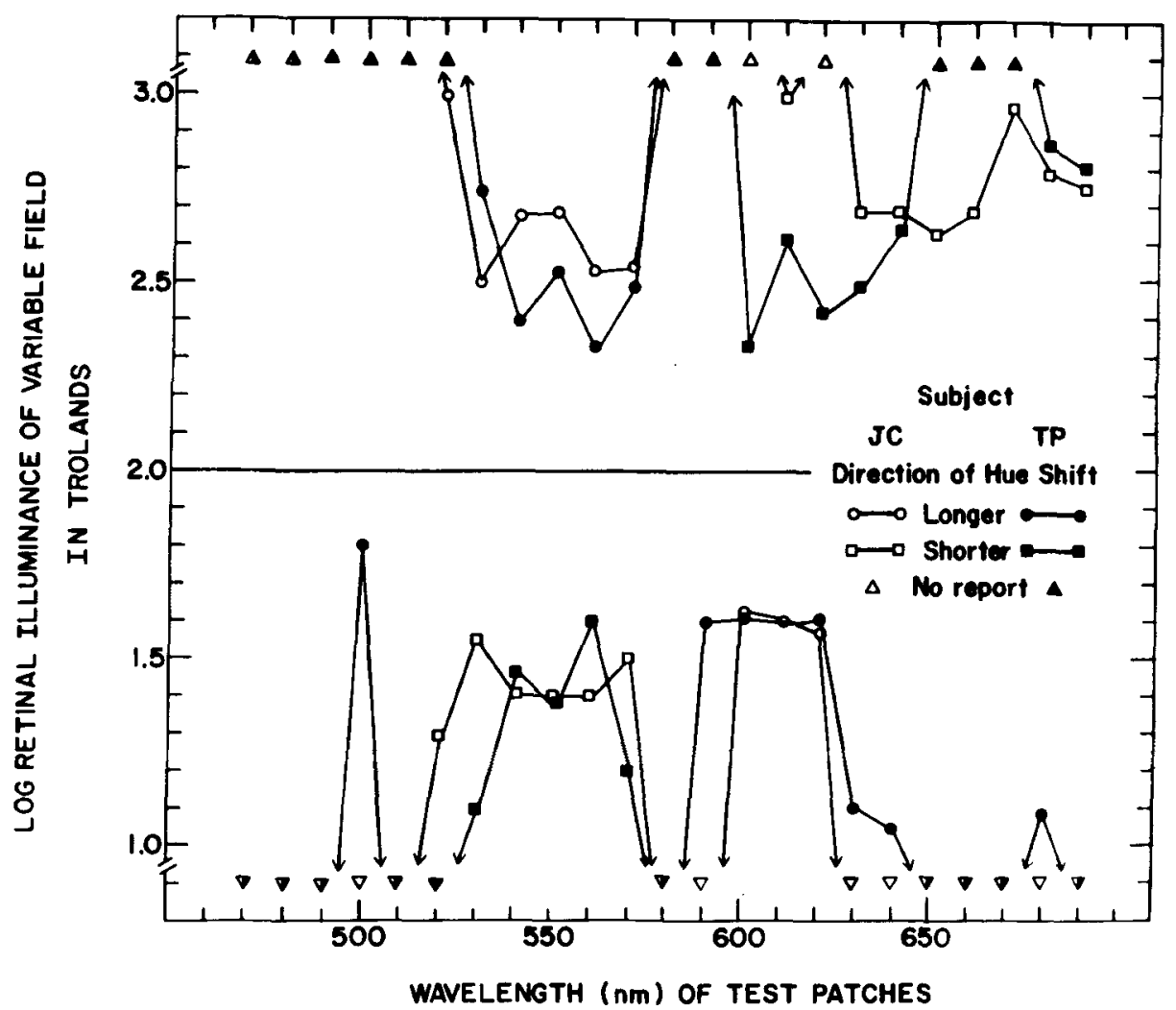

Fig. 2. The threshold luminance for perception of a hue shift as a function of wavelength. 
by the method of heterochromatic flicker photometry.

A flicker disc driven by a variable speed motor (Mt) was placed behind the mirror and a field stop, which just filled one of the test patches, was inserted behind the flicker disc. A bracketing method was used in which the $S$ was asked to state when minimal flicker occurred. The luminance of the surround was determined by using the zero order spectrum ("white" light) of the monochromator. First the white light was calibrated by flicker photometry and then a direct brightness match was made between the surround and (white) test patches. The color match for the two whites was not perfect, but a brightness match could be made without difficulty. The luminance reflected off the flicker disc was measured with an Ilford SEI exposure photometer.

\section{Subjects}

Two of the authors served as Ss. Both were graduate students in their twenties. They were tested on the Hecht-Shlaer anomaloscope and gave settings within the normal range.

\section{Procedure}

Thresholds were obtained at $10 \mathrm{~nm}$ intervals between $470 \mathrm{~nm}$ and $690 \mathrm{~nm}$, with the various wavelengths presented in random order. The illumination level for the standard test field was maintained at $2.0 \mathrm{log}$ trolands and the surround was set at $\mathbf{1 . 0}$ $\log$ troland. Initially, both test fields were set equal in brightness. The $\mathrm{E}$ then manipulated the luminance of the variable field in $0.1 \mathrm{log}$ unit steps in a modified method of limits procedure, always starting at the "equal" position (2.0 log trolands). Four to five sequences were completed at each wavelength, for both luminance increases and luminance decreases of the variable field. The $S$ responded after every trial, indicating any color difference between the fields. Four color names were used: blue, green, yellow, and red. For example: at $600 \mathrm{~nm}$, with 2.4 log trolands in the variable (right) field, Subject TP reported: "Right field yellower, left field redder" on four of the five ascending sequences.

The threshold for perceiving a hue shift was defined as the median luminance at which a hue difference was first reported.

At the beginning of each session, the $\mathrm{S}$ darkadapted for $5 \mathrm{~min}$. Both Ss were instructed to maintain fixation between the two fields. Three sets of observations were made and the median threshold of the three was computed. The experimental sessions lasted 2-3 $h$ and both Ss served about $40 \mathrm{~h}$ as observers.

\section{RESULTS AND DISCUSSION}

Figure 2 shows the luminance thresholds as a function of wavelength. The solid line at $2.00 \mathrm{log}$ trolands represents the constant luminance of the standard test patch. Since color names are correlated with specific portions of the spectrum, it is possible to analyze the direction of the hue shift. For example at wavelength $620 \mathrm{~nm}$, the median threshold for a luminance increment for Subject TP was $2.43 \mathrm{log}$ trolands. The color responses of the $S$ indicated that the brighter field was yellower and the dimmer field redder. Since color naming data (Beare, 1963; Boynton \& Gordon, 1965) indicate that the response "yellow" occurs at shorter wavelengths than the response "red," the hue shift of the brighter test patch was toward shorter wavelengths.

The direction of the hue shift is shown in Fig. 2. For stimulus increments between 520 and $570 \mathrm{~nm}$, the hue shift was toward longer wavelengths or yellow, while for stimulus decrements the shift was to shorter wavelengths or "green." Above $590 \mathrm{~nm}$, the shift for stimulus increments remained toward yellow which represents a shift to shorter wavelengths; while for stimulus decrements, the shift was to longer wavelengths, or red.

When the threshold points representing the same direction of shift are joined, the resulting functions appear similar for the two Ss with the exception of the hue shifts for stimulus increments in the range $600-660 \mathrm{~nm}$. In this region of the spectrum hue

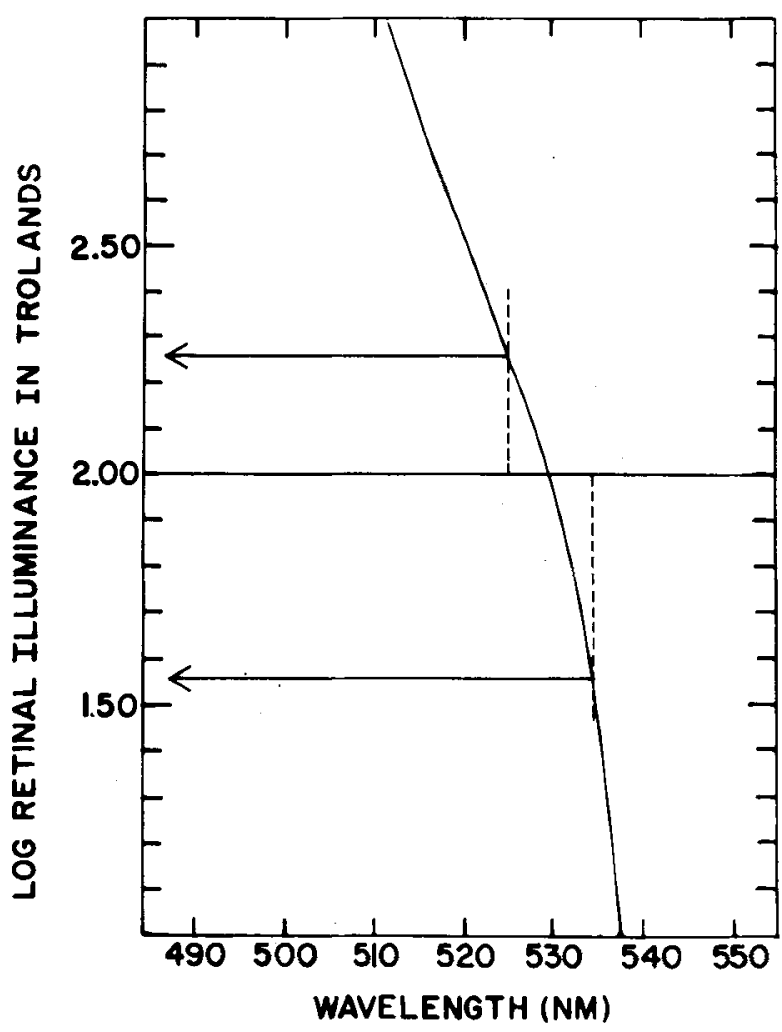

Fig. 3- Purdy's constant hue contour for wavelength $530 \mathrm{~nm}$ at $2.00 \mathrm{log}$ trolands. The dashed lines show the wavelength discrimination steps at $530 \mathrm{~nm}$. 
shifts were reported by Subject TP in the region $600-$ 640 and by Subject JC in the region $630-660$.

Other regions of the spectrum for which there was some subject variability are the regions $500-520 \mathrm{~nm}$ and $580-600 \mathrm{~nm}$. These regions correspond to the range of the "unique" hues corresponding to green and yellow (Boynton \& Gordon, 1965). The color names used by the Ss also indicate that the unique hues did occur in these regions of the spectrum. Figure 2 shows that near the unique hues, the hue shift thresholds have nearly one log unit difference in illuminance between the fields or the thresholds are unobtainable within one $\log$ unit difference. The thresholds then decrease to represent a luminance increment or decrement of about 0.4 to $0.6 \mathrm{log}$ unit in the spectral region between the unique hues.

Thresholds were generally not obtained for either stimulus increments or decrements between 470 and 490 , or for stimulus decrements beyond $650 \mathrm{~nm}$. Since unique "blue" may occur between $460-480 \mathrm{~nm}$ (Akita, Graham, \& Hsia, 1964; Boynton \& Gordon, 1965; Purdy, 1931), it is possible that failure to obtain thresholds in this region reflects the fact that the hue shift thresholds are large in the spectral region near the unique hues. Unfortunately there was not enough energy to obtain thresholds for wavelengths below $470 \mathrm{~nm}$.

Predicted luminance thresholds were calculated based on Purdy's (1937) constant hue contours and wavelength discrimination data obtained with a $3^{\circ}$ bipartite field at $1.20 \mathrm{log}$ troland (Pokorny \& Smith, 1967). It is assumed that wavelength discrimination for targets greater than $1^{\circ}$ is not grossly affected by luminance level in the range 1.00 to $3.00 \mathrm{log}$ trolands (Bedford \& Wysecki, 1958; McCree, 1960). The method of obtaining the predicted thresholds is shown in Fig. 3 , which gives Purdy's constant hue contour for wavelength $530 \mathrm{~nm}$ at $2.00 \mathrm{log}$ trolands. The wavelength discrimination step at $530 \mathrm{~nm}$ is calculated to be $4.7 \mathrm{~nm}$ in the sequence blue to red and $4.0 \mathrm{~nm}$ in the sequence red to blue (an average of two $O s$ ). Dashed lines are drawn, parallel to the luminance axis, at 526 and $534.7 \mathrm{~nm}$. The intersection of these dashed lines with the constant hue contour represents the luminance at which the hue associated with the variable is just noticeably different from the hue associated with the standard field.

Figure 4 shows the predicted luminance thresholds for the perception of a hue shift for the wavelength range $450 \mathrm{~nm}-645 \mathrm{~nm}$. The vertical lines represent

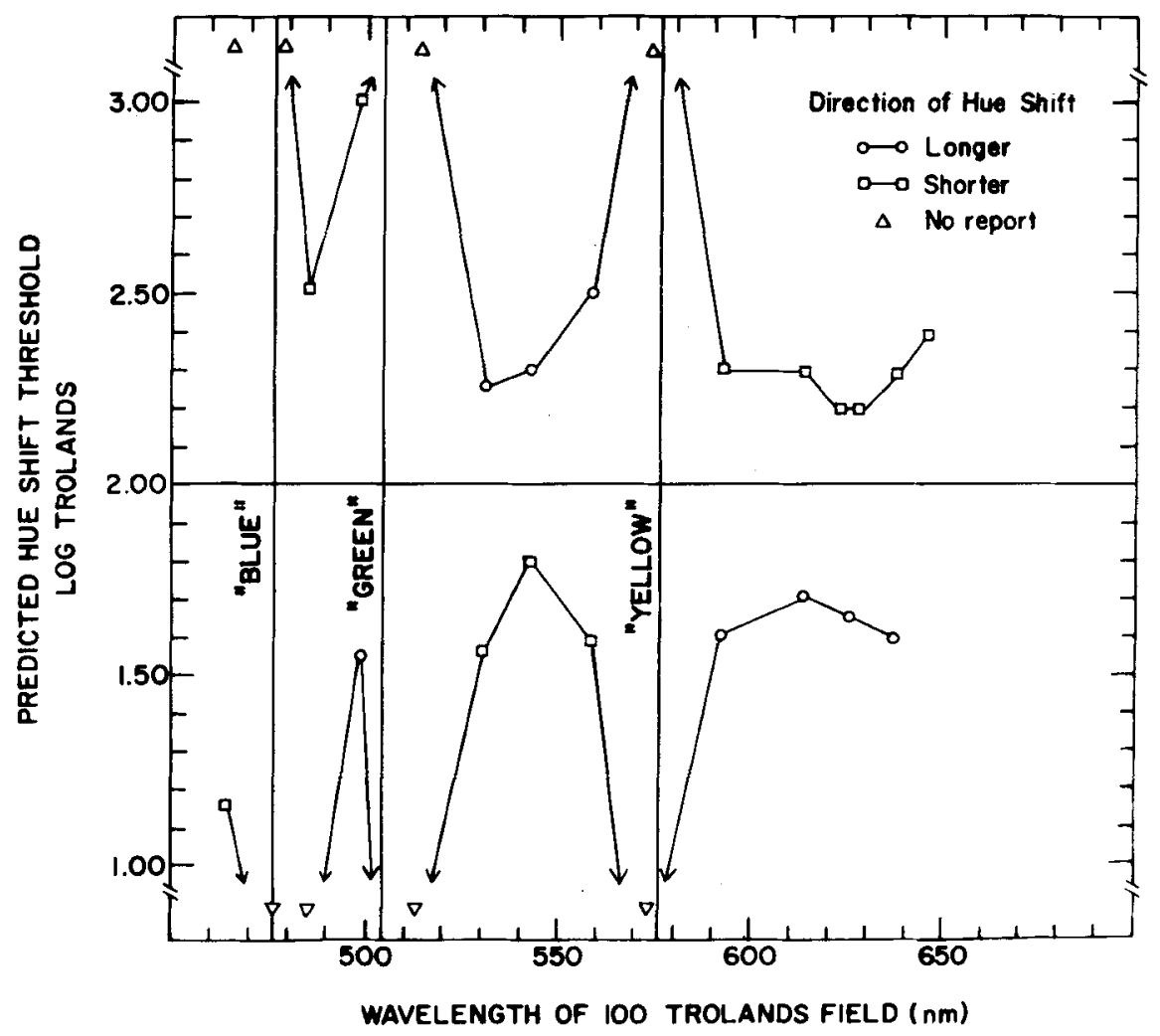

Fig. 4. Predicted luminance threshold for the Bezold-Brucke phenon enon calculated from Purdy's constant hue contours weighted by Pokomy and Smith's wavelength discrimination fi nction. 
Purdy's (1931) spectral unique hues. The predicted values show trends similar to those shown by the experimental data of Fig. 2. Purdy's data do not extend beyond $645 \mathrm{~nm}$ at $2.0 \mathrm{log}$ trolands, and thus no predictions are available for the deep red end of the spectrum. Close to the spectral unique hues, predicted hue shift thresholds may not be obtained or may represent nearly one log unit difference in illuminance between the fields. Between the unique hues the predicted thresholds represent a luminance decrement or increment of $0.2-0.3 \log$ unit. The major difference between the experimental and predicted thresholds is one of scale.

\section{References}

Akita, M., Graham, C. H., \& Hsia, x. Maintaining an absolute hue in the presence of different background colors. Vis. Res., $1964,4,539-556$

Akita, M., \& Graham, C. H. Maintaining an absolute test hue in the presence of different background colors and luminance ratios. Vis. Res., 1966, 6, 315-323.

Beare, A. C. Color-name as a function of wave-length. Amer. $J$. Psychol., 1963, 76, 248-256.

Bedford, R. E., Wysecki, G. W. Wavelength discrimination for point sources. J. Opt. Soc. Amer., 1958, 48, 129-135.

Boynton, R. M., \& Gordon, J. Bezold-Brücke hue shift measured by color-naming technique. J. Opt. Soc. Amer., 1965, 55, 78-86.
Dagher, M., Cruz, A., \& Plaza, L. Colour thresholds with monochromatic stimuli in the spectral region $530-630 \mathrm{~m} \mu$. In Visual problems of color, Vol. II. New York: Chemical Publishing Co., 1961. Pp. 23-32.

Luria, S. M. Color-name as a function of stimulus-intensity and duration. Amer. J. Psychol, 1967, 80, 14-27.

McCree, K. J. Small-field tritanopia and the effects of voluntary fixation. Optica Acta, 1960, 7, 317-323.

Pokomy, J., \& Smith, v. C. Wavelength discrimination in the presence of additive chromatic fields. (Abst). J. Opt. Soc. Amer., 1967, 57, 557-558.

Purdy, D. McL. Spectral hue as a function of intensity. Amer. J. Psychol., 1931, 43, 541-559.

Purdy, D. McL. The Bezold-Brücke phenomenon and contours for constant hue. Amer. J. Psychol., 1937, 49, 313-315.

\section{Notes}

1. This document is Technical Report No. 41, of Contract No. 266(46), between Columbia University and the Office of Naval Research. The work is part of the program of Project No. 142-404. Reproduction in whole or in part is permitted for any purpose of the United States government. Support has aiso been provided by the Institutional Scientific Research Pool of Columbia University. This study was performed in the laboratory of Clarence $\mathbf{H}$. Graham. We should like to thank him for his advice and for his critical reading of the manuscript.

2. Present address: Eye Research Laboratories, University of Chicago, 950 East 59th Street, Chicago, Illinois 60637.

3. Present address: Psychology Department. University of Pennsylvania, 106 College Hall, Philadelphia, Pennsylvania 19104

(Accepted for publication November $26,1967$. 